\title{
Adoption Level of Zinger Growers Regarding Zinger Cultivation Practices
}

\author{
Deepak Kumar Verma ${ }^{1}$, R.K Dohrey ${ }^{2}$, Shesh Narain ${ }^{3}$, Garima Tiwari ${ }^{4}$, \\ Manoj Kumar ${ }^{2 *}$ and Ravi Kumar Pandey ${ }^{2}$ \\ ${ }^{1}$ Department of Agricultural Extension, College of Agriculture, SVPUA\&T, \\ Modipuram, Meerut (U.P) 250110 \\ ${ }^{2}$ Department of Extension Education, NDUA\&T, Kumarganj, Faizabad- 224229 (U.P.), India \\ ${ }^{3}$ S.M.S (Agriculture Extension) K.V.K Mashodha Faizabad (U.P), India \\ ${ }^{4}$ IARI, Division of Agricultural Extension, New Delhi - 110012, India \\ *Corresponding author
}

\begin{tabular}{|c|c|}
\hline \multicolumn{2}{|r|}{ A B S T R A C T } \\
\hline & \multirow{6}{*}{$\begin{array}{l}\text { The study was conducted in Bundelkhand Region during the year } 2010-2011 \text {, To } \\
\text { know the adoption level of the Zinger growers regarding Zinger cultivation practices. } \\
\text { For this purpose } 4 \text { villages' peripheral and } 4 \text { distant villages were randomly selected } \\
\text { from Bundelkhand region. From each village } 10 \text { respondents were purposively } \\
\text { selected. Thus total sample size was of } 80 \text { Zinger growers for the study. It was } \\
\text { observed that } 36.04 \% \text { peripheral farmers adopting improved varieties, } 51.87 \% \text { field } \\
\text { preparation practices, } 70.83 \% \text { sowing rainfed and irrigated conditions, } 58.33 \% \\
\text { adopting optimum seed rate, } 53.33 \% \text { line sowing, } 69.16 \% \text { sowing optimum depth, } \\
50.83 \% \text { adopting thinning practices, } 49.16 \% \text { adopted balance use of fertilizers and } \\
34.16 \% \text { adopting storage practices. While } 33.91 \% \text { distant farmers were using } \\
\text { improved varieties, } 43.95 \% \text { field preparation, } 45.83 \% \text { sowing Zinger in rainfed and } \\
\text { irrigated conditions, } 40.83 \% \text { using optimum seed rate, } 44.16 \% \text { line sowing adopted, } \\
41.66 \% \text { sowing optimum depth, } 39.16 \% \text { adopting thinning practices, using optimum } \\
\text { irrigation, } 41.66 \% \text { using balance fertilizers and } 22.33 \% \text { adopting storage practices. } \\
\text { There were minor difference found in between regarding peripheral farmers and } \\
\text { distant farmers regarding adoption of plant protection measure in Zinger cultivation. }\end{array}$} \\
\hline & \\
\hline $\begin{array}{l}\text { Adoption level, } \\
\text { Cultivation } \\
\text { Practices. }\end{array}$ & \\
\hline Article Info & \\
\hline $\begin{array}{l}\text { Accepted: } \\
\text { 22 January } 2017 \\
\text { Available Online: } \\
\text { 10 February } 2017\end{array}$ & \\
\hline & \\
\hline
\end{tabular}

\section{Introduction}

India has been the "Home of spices" since time immemorial. It is the world's largest producer, consumer and exporter of seed spices which are being cultivated widely in the country over different agro-climatic zones. Zinger is used as a crude drug to enhance the body's resistance and is prescribed in amebiasis. It is a potent antimicrobial agent. Due to its multiple properties, ginger is used to cure cough, gastric problem, stomachache, bloat as well as urinary troubles. In view of the above medicinal and nutritional properties of Zinger, the production technology of zinger cultivation is essential. Keeping this fact in view the present study was conducted in Jhansi district. Spices are extensively used as flavoring agent in various food products and in pharmaceutical industries in preparation of various Ayurvedic medicines. The aromas in 
the spices are due to presence of volatile oil. The volatile oil content varies from 0.2 to 1.7 per cent (in coriander) to 13.2 per cent (in clove). Some spices crops such as chillies, ginger, black pepper, curry leaf etc., are well known for their peculiar pungency. The pungency in spices is due to presence of alkaloids like piperine in black - pepper and capsaicin in chillies, some spices like rai well known as preservative. In Unani-system, Zinger is used as a crude drug to enhance the body's resistance and is prescribed in amebiasis. It is a potent antimicrobial agent. Due to its multiple properties Zinger is used to cure cough, gastric problem, stomachache, bloat as well as urinary troubles. It is a good mouth wash and as an anticlimactic ayurvedic like "Jeevan Rakhask Sudha" and "ayurvedic churna" are mainly prescribed where as "Jeevan Rakhask Sudha" is adviced for the cure of headache, chest pain and backache and "ayurvedic churna" specified for cure of constipation, and acidity etc. In view of the above medicinal and nutritional properties of Zinger it is generally given to the ladies after delivery.

\section{Materials and Methods}

The present study was conducted in the purposely selected Chittorgarh district of Jhansi. There are fourteen tehsils in Chittorgarh district, out of which Dungla tehsil was selected purposively under Zinger cultivation. Further, a comprehensive list of all the villages where the Zinger crop is being grown was prepared in consultation with the personnel of Revenue and Agriculture Department. Eight villages (four peripheral and four distant) were selected from the list on the basis of maximum area under Zinger cultivation. For the selection of respondents, a comprehensive list of farmers who were Zinger growers was prepared from each identified peripheral and distant village with the help of village Patwari and Agriculture
Supervisor of respective village. From the list so prepared, ten Zinger growers were selected randomly from each identified village. Thus, the total 80 respondents (40 farmers from peripheral villages and 40 farmers from distant villages) were selected for the present investigation.

\section{Results and Discussion}

\section{Adoption of improved zinger production practices among the farmers}

Third part of this chapter deals with the extent of adoption of improved Zinger production practices among the farmers. In the modern era new things are being inverted by agricultural scientists but all the innovations are not being adopted by many of the members of social system. Adoption of an innovation depends on many factors viz., awareness and knowledge of adopters, innovativeness, characteristics of innovations etc. It is generally assumed that if an individual has more knowledge about different aspects of technologies, he is likely to adopt the innovations with higher speeds. Efficient transfer of innovations and their application to field situation are key to economic development. Several transfer of technology (TOT). Programmes are in operation to help farmers to adopt the new technologies in our country. Still there exist a wide gap between the technology available at the research farm and its adoption by the farmers. Keeping this in mind an attempt has been made to know the extent of adoption of improved Zinger production technology. The results are presented under following subsections.

\section{Distribution of respondents on the basis of their level of adoption}

To get the overall view of adoption level of the respondents, they were divided into three 
groups viz. (i) low adoption group $(<34$ score) (ii) medium adoption group (34 to 54 score) and (iii) high adoption group (> 54 score). The groups were based on the calculated mean and SD of the adoption scores obtained by the respondents. The results of the same are presented in table 1.

Data presented in table 1 depict that majority (61.25 per cent) of the total respondents were belonged to the medium adoption group whereas, 21.25 per cent respondents were in low adoption group and remaining 17.50 per cent Zinger growers to be observed in the high level of adoption group about Zinger production technology.

Further, among the categories of Zinger growers it was observed that in high adoption group 27.50 per cent respondents were found to be from peripheral farmers category followed by 7.50 per cent respondents from distant farmers category. In the medium adoption group 55.00 per cent respondents from peripheral farmers category and 67.50 per cent respondents were from distant farmers category. Whereas, in low adoption group 17.50 per cent respondents were from peripheral farmers group and 25.00 per cent from distant farmers category. From the above results it could be concluded that peripheral farmers possessed higher level of adoption of Zinger production practices than distant farmers. It can be further concluded that 82.0 per cent respondents from peripheral category were to be observed either from medium or from high adoption group. Whereas 75.00 per cent distant farmers adopted Zinger technology medium to lower level in the study area. These findings are similar with the finding of Desai et al. (1996) who reported that majority $(63.41 \%)$ of the respondents expressed moderate adoption followed by high $(20.00 \%)$ and low adoption $(16.95 \%)$ due to adoption of recommended cumin cultivation practices.
Individual aspect-wise extent of adoption of Zinger growers was worked out with the help of mean per cent score and rank order. The results of the same have been presented in table 1 .

Table 2 depicts the adoption of recommended improved variety seed with the 36.04 and 32.91 MPS by peripheral and distant farmers, who have adopted improved varieties like Lam selection-1, Gujarat Zinger-1 in the study area respectively. Likewise the peripheral and distant Zinger growers adopt 51.87 and 43.95 MPS recommended techniques of field preparation of Zinger, respectively. The extent of adoption was 49.16 and, 41.66 MPS among peripheral and distant farmers about adoption of techniques of nitrogenous fertilizer application. It was found that 32.50 MPS peripheral and 26.66 MPS distant farmers were using urea as major source of nitrogen application along with recommended dose at sowing time and half does at 25 days after sowing.

On the other hand application of phosphatic fertilizer, the extent of adoption was 43.33 and 37.50 MPS among the peripheral and distant of farmers, respectively. Whereas, the adoption about recommended potasic fertilizers was observed 38.33 and 35.83 MPS among the peripheral and distant farmers respectively.

The study of table 2 further reveals that the extent of adoption about recommended sowing time under rainfed condition was 70.83 and 45.83 MPS among peripheral and distant zinger growers, respectively. Likewise, the peripheral and distant zinger growers had extent of adoption about recommended sowing time under irrigated condition was 73.33 and 49.16 MPS among the peripheral distant farmers, respectively and ranked first by both the category of respondents. 
Table.1 Distribution of respondents on the basis of their level of adoption of improved zinger production practices among the farmers

\begin{tabular}{|l|l|l|l|l|l|l|l|}
\hline S. No. & Adoption level & \multicolumn{2}{c|}{$\begin{array}{c}\text { Peripheral } \\
\text { farmers }(\mathbf{n}=\mathbf{4 0})\end{array}$} & $\begin{array}{c}\text { Distant farmers } \\
(\mathbf{n = 4 0 )}\end{array}$ & \multicolumn{2}{c|}{ Total } \\
\hline & & $\mathbf{F}$ & $\mathbf{\%}$ & $\mathbf{F}$ & $\mathbf{\%}$ & $\mathbf{F}$ & \% \\
\hline 1. & Low (<34) & 7 & 17.50 & 10 & 25.00 & 17 & 21.25 \\
\hline 2. & Medium (34 to 54) & 22 & 55.0 & 27 & 67.50 & 49 & 61.25 \\
\hline 3. & High (> 54) & 11 & 27.50 & 3 & 7.50 & 14 & 17.50 \\
\hline & Total & 40 & 100 & 40 & 100 & 80 & 100 \\
\hline
\end{tabular}

$\mathrm{F}=$ Frequency, $\%=$ Per cent

Table.2 Extent of adoption of production practices by zinger growers $(\mathrm{N}=80)$

\begin{tabular}{|c|c|c|c|c|c|c|c|}
\hline \multirow{2}{*}{\begin{tabular}{|l} 
S. \\
No.
\end{tabular}} & \multirow[t]{2}{*}{ Practices } & \multicolumn{2}{|c|}{$\begin{array}{c}\text { Peripheral } \\
\text { farmers }\end{array}$} & \multicolumn{2}{|c|}{$\begin{array}{l}\text { Distant } \\
\text { farmers }\end{array}$} & \multicolumn{2}{|c|}{ Total } \\
\hline & & MPS & $\mathrm{R}$ & MPS & $\mathrm{R}$ & MPS & $\mathrm{R}$ \\
\hline 1. & Improved varieties & 36.04 & 15 & 32.91 & 15 & 34.47 & 15 \\
\hline 2. & Field preparation & 51.87 & 7 & 43.95 & 6 & 47.91 & 7 \\
\hline 3. & Nitrogenous fertilizer application & 49.16 & 9.5 & 41.66 & 7.5 & 45.41 & 9 \\
\hline 4. & $\begin{array}{l}\text { Techniques of nitrogenous } \\
\text { fertilizer application }\end{array}$ & 32.50 & 18 & 26.66 & 17 & 29.58 & 17 \\
\hline 5. & Phosphatic fertilizer application & 43.33 & 13 & 37.50 & 11.5 & 40.41 & 12 \\
\hline 6. & $\begin{array}{l}\text { Potassic fertilizer needs to be } \\
\text { applied }\end{array}$ & 38.33 & 14 & 35.83 & 13 & 37.08 & 14 \\
\hline 7. & $\begin{array}{l}\text { Month of sowing under rainfed } \\
\text { conditions }\end{array}$ & 70.83 & 2 & 45.83 & 4 & 58.33 & 2 \\
\hline 8. & $\begin{array}{l}\text { Month of sowing under irrigated } \\
\text { conditions }\end{array}$ & 73.33 & 1 & 49.16 & 1 & 61.24 & 1 \\
\hline 9. & Optimum seed rate adopted & 58.33 & 5 & 40.83 & 9 & 49.58 & 5 \\
\hline 10. & Sowing technique adopted & 60.00 & 4 & 47.50 & 2 & 53.75 & 4 \\
\hline 11. & Line spacing maintained & 53.33 & 6 & 44.16 & 5 & 48.74 & 6 \\
\hline 12. & Depth of sowing & 69.16 & 3 & 41.66 & 7.5 & 55.41 & 3 \\
\hline 13. & Thinning performed & 50.83 & 8 & 39.16 & 10 & 44.99 & 10 \\
\hline 14. & Number of irrigation given & 48.33 & 11 & 37.50 & 11.5 & 42.91 & 11 \\
\hline 15. & Aphid control measures applied & 9.16 & 19 & 8.95 & 19 & 9.05 & 19 \\
\hline 16. & Powdery mildew control applied & 8.95 & 20 & 8.75 & 20 & 8.85 & 20 \\
\hline 17. & Blight control applied & 33.33 & 17 & 33.33 & 14 & 33.33 & 16 \\
\hline 18. & $\begin{array}{l}\text { Precaution taken during harvesting } \\
\text { of crop }\end{array}$ & 44.58 & 12 & 31.45 & 16 & 38.01 & 13 \\
\hline 19. & Crop yield obtained & 49.16 & 9.5 & 46.25 & 3 & 47.70 & 8 \\
\hline \multirow[t]{2}{*}{20.} & Storage techniques applied & 34.16 & 16 & 22.33 & 18 & 28.24 & 18 \\
\hline & & & \multicolumn{3}{|c|}{$\left(r_{\mathrm{s}}\right)=0.902 * *$} & & \\
\hline
\end{tabular}


Figure.1 Distribution of respondents on the basis of their level of adoption of improved zinger production practices among the farmers

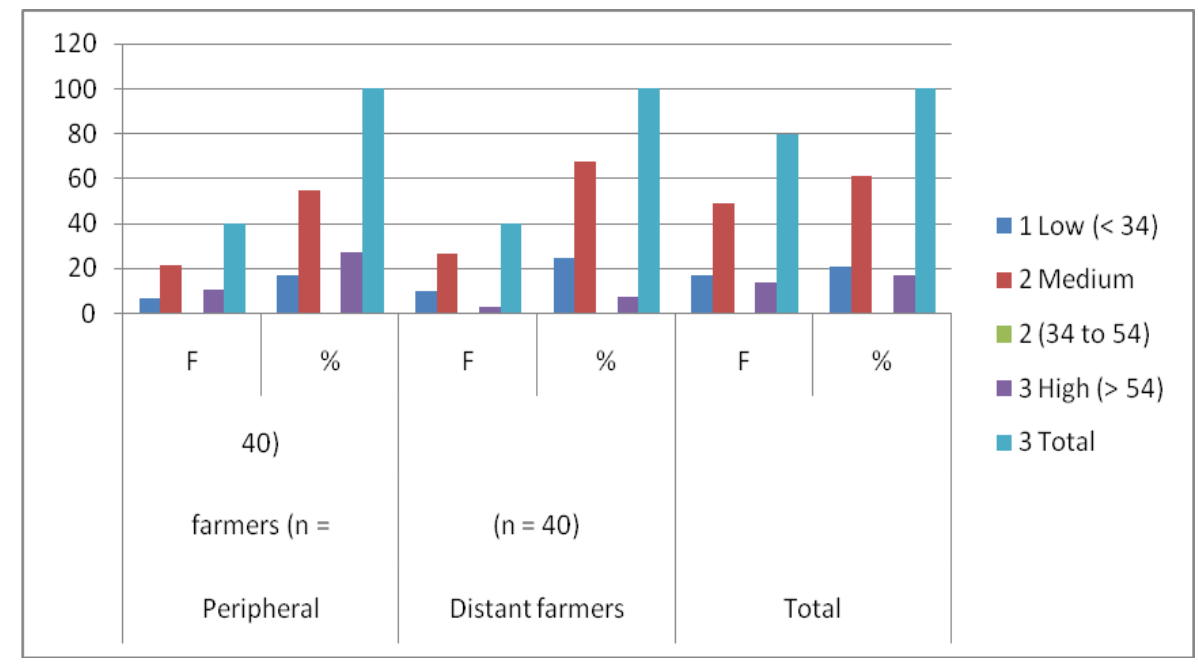

It was found that extent of adoption about recommended seed rate was 58.33 and 40.83 MPS peripheral and distant farmers, respectively. It was noted that majority of respondents were using recommended seed rate of 2 to $2.5 \mathrm{~kg} / \mathrm{ha}$ for Zinger cultivation in. the study area. The adoption of sowing technique was 60.00" and 47.50 MPS in peripheral farmers and distant farmers and ranked fourth and second by the peripheral and distant categories of farmers. It was found that adoption of row to row spacing was maintained by 53.33 and 44.16 MPS in peripheral and distant category of respondents, respectively. It was also found that recommended depth of sowing of Zinger with 69.16 and 41.66 MPS in peripheral and distant farmers, respectively. This aspect was ranked third by the peripheral farmers, while distant farmers ranked it $7.5^{\text {th }}$ in order of adoption of Zinger cultivation practices.

Further analysis of table 2 indicates that the extent of adoption of thinning practice performed was 50.83 and 39.16 MPS" in the peripheral and distant farmers, respectively. It was found that recommended numbers of irrigations were given to crop with 48.33 and 37.50 MPS among peripheral and distant
Zinger growers, respectively. Aphid control measures were applied by 9.16 and 8.95 MPS peripheral and distant category of respondents, respectively.

Powdery mildew control measures were applied by 8.95 and 8.75 MPS peripheral and distant farmers, respectively and it was ranked last by both the category of respondents. The blight control measures were applied with recommended pesticides with 33.33 and 33.33 MPS peripheral and distant farmers. Recommended precautions were adopted during harvesting of crop with 44.58 and 31.45 MPS by the peripheral and distant respondents, respectively. The recommended crop yield was obtained with by 49.16 and 46.25 MPS by peripheral and distant categories of respondents, respectively. The study of table 2 further reveals that recommended storage techniques were adopted with 34.16 and 22.33 MPS by peripheral and distant Zinger growers, respectively. It means the respondents were not aware about proper storage techniques.

This table 2 concludes that the maximum and minimum adoption in peripheral farmers was 8:95 to 73.33 MPS, while in case of distant 
farmers it adoption was 8.75 to 49.16 MPS among all the improved Zinger cultivation practices. Further, it was noted that peripheral farmers had more adoption than distant farmers about most of the Zinger cultivation practices; still there is a gap in the adoption of improved Zinger production technology. To improve the extent of adoption in both the categories of farmers intensive and timely training programmes should be organized in the study area. The table 2 further reveals that the calculated rank order correlation $\left(\mathrm{r}_{5}\right)$ value was 0.902 which was found to be statistically significant at 1 per cent level of significance. Thus, it can be inferred that there was a significant correlation between ranks assigned to extent of adoption of improved Zinger cultivation practices by peripheral and distant farmers. The present findings are in line with the finding of Puranik and Verma (1992), who found that practice wise adoption level of respondents revealed that respondents had highest adoption in the practice of irrigation management and harvesting methods of sweet potato. While poor adoption was found in insect-pest and disease control aspects in sweet potato crop.

In conclusion, it was found that 61.25 MPS of the total respondents possessed medium adoption level about Zinger production practices. It was observed that 61.24 MPS peripheral and distant farmers complete sowing operations in recommended period. (Under rainfed conditions 58.33 MPS farmers of both the categories complete their sowing operations. 55.41 MPS peripheral and distant farmers use recommended sowing depth. Powdery mildew control measures were adopted only by 8.55 MPS farmers of both the categories. The aphid control measures were applied by 9.05 MPS peripheral and distant farmers.

\section{References}

Desai, C.P., Pandey, D.N., Patel, M.R. and Patei, A.A. 1996. Farmers satisfaction with adoption of cumin cultivation. Gujarat Agri. University Res. J., 21(2): 72-75.

Krishnamurthy, A.T., Kumar, V.B.S., Basavaraju, H.K. and Ahamed, B.Z. 2008. Adoption level and constraints in adoption of improved practices among vegetable growers of Chikmagalur district, Karnataka. Environ. Ecol., 26(2A): 888-891.

Nwaobiala, C.U. and Nwosu, I.E. 2013. Analysis Of Factors Influencing Adoption Of Okra Production Technologies Among Farmers In Enugu State, Nigeria J. Agri. Social Res., Vol. 13, No.2,

Nwaobiala, C.U. and Ogbonna, M.O. 2014. Adoption Determinants and Profitability Analysis of Okra Farming In Aninri Local Government Area (LGA) of Enugu State, Nigeria Discourse J. Agri. Food Sci., www.resjournals.org/JAF

Puranik, R.P. and Verma, P.R. 1992. Adoption of sweet potato technology, Indian $J$. Extension Education, 28: 114-116.

Singh, P.K., Barman, K.K. and Varshney, J.G. 2011. Adoption behaviour of vegetable growers towards improved technologies. Indian Res. J. Extension Education, 11(1): 62-65.

\section{How to cite this article:}

Deepak Kumar Verma, R.K Dohrey, Shesh Narain, Garima Tiwari, Manoj Kumar and Ravi Kumar Pandey. 2017. Adoption Level of Zinger Growers Regarding Zinger Cultivation Practices Int.J.Curr.Microbiol.App.Sci. 6(2): 1360-1365. doi: http://dx.doi.org/10.20546/ijcmas.2017.602.154 